\title{
Article
}

\section{Current and prospective pharmacotherapies for the treatment of pleural mesothelioma}

Bakker, Emyr, Guazzelli, Alice, Krstic-Demonacos, Marija, Sotgia, Federica, Lisanti, Michael and Mutti, Luciano

Available at http://clok.uclan.ac.uk/21177/

Bakker, Emyr ORCID: 0000-0002-0091-1029, Guazzelli, Alice, KrsticDemonacos, Marija, Sotgia, Federica, Lisanti, Michael and Mutti, Luciano (2017) Current and prospective pharmacotherapies for the treatment of pleural mesothelioma. Expert Opinion on Orphan Drugs, 5 (6). pp. 455-465.

It is advisable to refer to the publisher's version if you intend to cite from the work. http://dx.doi.org/10.1080/21678707.2017.1325358

For more information about UCLan's research in this area go to http://www.uclan.ac.uk/researchgroups/ and search for <name of research Group>.

For information about Research generally at UCLan please go to http://www.uclan.ac.uk/research/

All outputs in CLoK are protected by Intellectual Property Rights law, including Copyright law. Copyright, IPR and Moral Rights for the works on this site are retained by the individual authors and/or other copyright owners. Terms and conditions for use of this material are defined in the policies page.

\section{CLoK}

Central Lancashire online Knowledge www.clok.uclan.ac.uk

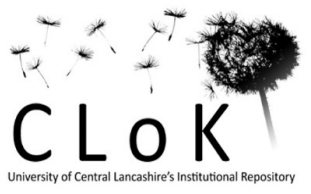




\section{ACCEPTED MANUSCRIPT}

This is an Accepted Manuscript of an article published by Taylor \& Francis in Expert Opinion on Orphan Drugs on $27^{\text {th }}$ April 2017, available online: http://www.tandfonline.com http://dx.doi.org/10.1080/21678707.2017.1325358

Bakker E, Guazzelli A, Krstic-Demonacos M, Lisanti M, Sotgia F, Mutti L. Current and prospective pharmacotherapies for the treatment of pleural mesothelioma. Expert Opinion on Orphan Drugs, 5(6), 455-465 (2017) 


\title{
Current and prospective pharmacotherapies for the treatment of pleural mesothelioma
}

\begin{abstract}
Introduction

Mesothelioma is a rare asbestos-linked cancer with an expected incidence peak between 20152030. Therapies remain ineffective, thus developing and testing novel treatments is important for both oncologists and researchers.
\end{abstract}

\section{Areas Covered}

After describing mesothelioma and the shortcomings of current therapies, the article discusses numerous therapies in turn such as immunotherapy (passive and active), gene therapy (such as suicide gene therapy) and targeted therapy such as tyrosine kinase inhibitors. The bases for different therapies and clinical trials at different phases are also described. The article concludes by detailing possible reasons for therapy failure.

\section{Expert Opinion}

Despite the many attempts to uncover new therapeutic options, mesothelioma is still an orphan disease, complicated by factors such as the inflammatory microenvironment and low mutational load. Our opinion is that uncovering the biological mechanisms behind mesothelioma development will assist therapy development. The lack of efficacy of tyrosine kinase inhibitors and modest anti-angiogenic activity indicates a less relevant role for tumour cell proliferation and neoangiogenesis, thus the shortcut of treating mesothelioma with therapies from other cancers may be unsound. Conversely, many lines of evidence indicate that focussing on the survival mechanisms that tumour cells exploit may yield better therapeutics, particularly nutrition and cellular machinery.

\section{Introduction}

Mesothelioma is an uncommon form of cancer arising from mesothelial cells which line the membranes of organs including the heart (pericardial mesothelioma), testes (testicular mesothelioma), abdomen (peritoneal mesothelioma) and the lungs (pleural mesothelioma) ${ }^{1}$. Of these four subtypes, peritoneal and pleural mesothelioma account for the vast majority of cases in mesothelioma (upwards of 90\%), whilst pleural mesothelioma is overall the most prevalent, accounting for $68-85 \%$ of all mesothelioma cases ${ }^{2}$.

Malignant pleural mesothelioma (MPM) affects significantly more men than women, at a ratio of $4: 1$, usually at advanced age ( $>65$ years old $)^{3}$. More men than women are affected by the disease due to workplace exposure. Approximately 2500 cases of MPM occur per year in the United States per year, whilst 5000 patients in Western Europe die from the disease each year ${ }^{3}$. Although a rare disease, there is an urgent need to develop new therapeutics as the fatalities from the disease are expected to increase over the next few years, in part due to the long latency period (approximately 50 years) from asbestos exposure to disease onset ${ }^{4,5}$. It is anticipated that the disease incidence will plateau between 2015-2030, and given the poor clinical outcome of current treatments there is a clear, urgent need to develop new therapeutics to improve patient care and address the oncoming surge of MPM cases ${ }^{5}$. 
This review will cover current treatment options for malignant pleural mesothelioma - both pharmacotherapies and other options such as surgery - in addition to discussing prospective novel therapies for the disease. A variety of topics will be discussed, including drugs used in the clinic at present such as cisplatin, pemetrexed and gemcitabine, as well as immunotherapeutic options such as tremelimumab and other immune checkpoint inhibitors such as nivolumab and pembrolizumab that are currently under investigation in early phase clinical trials. Lastly, the review closes with an Expert Opinion summarising the contents of the article and arguing the strengths and weaknesses of the different approaches discussed throughout the review.

\section{Body}

\subsection{Current treatments for mesothelioma}

As stated in the Introduction, malignant pleural mesothelioma presents an unmet challenge due to the anticipated surge in cases in the coming years and the current poor clinical outcome. There is also a high interest in this cancer due to it being largely a man-made epidemic through the use of asbestos ${ }^{6}$. Despite it being established that asbestos is linked to MPM development, many countries have been slow to implement its removal, thus elevating the chances of further diagnoses in the future. Further complicating the issue is the fact that the fire-retardant and insulating properties of asbestos mean that it has been used as part of the structural support of numerous buildings, and should these buildings be damaged millions of people could be exposed to it and potentially develop mesothelioma ${ }^{3}$.

MPM is treated in different ways (including surgery, radiotherapy and chemotherapy) which may vary depending on the stage of the cancer. Stage I MPM is characterised by minimal tumour growth, isolated to the parietal pleura with possible involvement of the visceral pleura. Stage II MPM is characterised by superficial tumour growth on all pleural membranes, or involvement of the diaphragmatic muscle or lung parenchyma. Notably, Stage I and II MPM patients have a tumour that may be resectable and thus treatable by surgery ${ }^{3}$. However, patients are commonly diagnosed at later stages, reducing the treatability of the disease by surgery.

Stage III MPM represents the most common stage at clinical diagnosis, and represents patients whose tumour has metastasised to areas such as lymph nodes, whilst Stage IV is characterised by the tumour invading the spine or ribs, with potential distant metastases, as well as other key clinical features ${ }^{3}$.

Unfortunately, no treatment regimen for MPM has demonstrated real capability to improve these patients' survival even though standard therapies for MPM do exist. They are of two kinds: one with more "curative" intent, and the other as palliative care to provide relief from symptoms. Opinions on suggested criteria for which approach is taken have been detailed previously ${ }^{5}$ such as deciding that curative intent should be taken if the patient is below seventy years old, has a cancer not in the advanced stages, has no significant cardiopulmonary complications, and has no relevant accompanying disease, whilst palliative care may be employed when the patient has a poor general condition and nutritional state, has advanced stage cancer or has sarcomatoid or biphasic mesothelioma at any stage ${ }^{5}$. Sarcomatoid mesothelioma, although a very rare form of mesothelioma, is a notoriously difficult cancer to treat and has a very poor clinical outcome ${ }^{7}$. 
Early stages of the cancer may be treated by surgery, with the desirable outcome being complete resection of the tumour but this is applicable only for a minority of patients due to the fact that most diagnoses occur at advanced tumour stages ${ }^{3,8,9}$. Surgery may also be used as a palliative therapy, serving to reduce symptoms and eliminate the bulk of the tumour mass (this is known as cytoreduction). Multiple types of surgery are employed, such as extrapleural pneumonectomy and pleurectomy/decortication ${ }^{10}$. Surgery alone, for those with resectable tumours, improves clinical outcomes. However, more effective outcomes are obtained when surgery is combined with adjuvant therapy such as chemotherapy or radiotherapy, with survival increasing slightly from ten months to twenty months ${ }^{8,11,12}$. Despite this, a systematic review carried out by Papaspyros and Papaspyros indicates that results from surgery are conflicting, with some studies indicating poor survival or no difference between patients treated surgically and those not, whilst the overall thought is that surgery as part of trimodality therapy offers long-term survival ${ }^{13}$. However, the authors also indicated that specialised centres demonstrated better results, which may present a complication in translating observed therapeutic benefits to the wider population ${ }^{13}$.

In addition to surgery, adjuvant chemotherapy and radiotherapy may be used in the treatment of MPM. Preclinical studies have demonstrated that radiotherapy may enhance the efficacy of an immune checkpoint inhibitor, however data remains largely preliminary ${ }^{8,14}$. Ultimately, single-modality therapy is generally less effective than multimodal therapy. Adjuvant chemotherapy is also supposed to target distant metastases ${ }^{9}$.

The cornerstone of chemotherapy for MPM is platinum-based drugs such as cis-platinum, which are often in combination with anti-folate agents as first-line therapy for advanced stage MPM when the tumour cannot be resected ${ }^{15}$. However, although some patients respond to this therapy there is no standard second-line therapy ${ }^{16}$. Other chemotherapy drugs utilised in the treatment of MPM include etoposide, doxorubicin, pemetrexed and gemcitabine. Generally, combination treatments of different chemotherapeutic drugs have shown more effective outcomes ${ }^{17}$. One combination that has been shown to achieve a slight improvement of survival is combination of pemetrexed with cisplatin ${ }^{18,19}$. However, although this study was an improvement in survival (of 2.8 months), successful therapy for MPM is obviously still lacking.

The lack of effective therapy for MPM highlights a very clear need to develop novel compounds and treatments to address the poor survival rate. There are several emerging therapies for mesothelioma which are at different stages of clinical development and usage, one of which is immunotherapy.

\subsection{Immunotherapy}

Immunotherapy in general refers to the idea of killing the cancer cells not by drugs targeting the cancer cells, but by using drugs or other therapeutic agents to facilitate immune-mediated anti-tumour effects. For MPM, it has been shown that lymphocyte infiltration to the tumour correlated with better prognosis in patients, highlighting the justification and potential of harnessing the power of the immune system ${ }^{20,21}$. A detailed review on different approaches to immunotherapy for MPM can be found by Grégoire (2010) ${ }^{21}$.

Before developing immunotherapeutic treatments for mesothelioma, it is important to first understand the immunophenotype of mesothelioma patients. Studies have shown that although leukocyte counts in patients were not altered overall, there was a shift in the subtypes that 
promoted tumour growth - for example there was a marked reduction in the levels of cytotoxic t-lymphocytes ${ }^{21,22}$. It has been shown in several cases that lymphocytes infiltrate the solid mesothelioma tumour and that immune cell-tumour associations are also present in pleural effusions; however, despite this, immune systems of patients are often tolerant towards the cancer growth ${ }^{21,23}$. Thus enhanced understanding of the reasons behind this is crucially important prior to designing immunotherapeutic agents, so as to target the facets of the immune system that are over- or underactive.

The immune response can be harnessed for therapeutic targets through passive immunotherapy and active immunotherapy. Passive immunotherapy has been described as an approach whereby effectors are isolated, "trained" in vitro and then re-injected into the patient to promote an anti-tumour effect. By contrast, active or adaptive immunotherapy refers to the approach of stimulating the immune system (i.e. through antigen presentation), thus triggering an immune response against the cancer. ${ }^{21}$. Generally, one problem with passive immunotherapy is that it is probable that the therapeutic benefit will be short-term, whereas active immunotherapy may have a more long-term approach to disease control ${ }^{24}$.

\subsubsection{Passive Immunotherapy}

There are numerous approaches to passive immunotherapy such as the use of cytokines, monoclonal antibodies, and activated T-lymphocytes ${ }^{18,21}$. It has been shown that cytokines such as interleukins stimulate the immune system against viruses and tumours, and it is hypothesised that this stimulation could be harvested to reduce tumour growth. One phase II study utilised interleukin-2 treatment for mesothelioma patients and found that those who responded to therapy had a statistically significant increase in median survival compared to non-responders ${ }^{25}$. However, conflicting findings on interleukin-2 treatment have been reported 18 , potentially due to different administration methods, and toxicity and side-effects of interleukin-2 treatment have been reported ${ }^{26}$ This and the conflicting reports provide a clear example of the challenge of harnessing the power of the immune system.

Although immune checkpoints are crucial within a healthy body for regulating self-tolerance and protecting healthy tissues during the immune response, it is increasingly clear that immune checkpoints are hijacked during the process of cancer development - for comprehensive coverage of blocking immune checkpoints in cancer as therapy, see Pardoll (2012) ${ }^{27}$. In brief, tumour resistance to the immune system typically arises through overexpression of inhibitory ligands that blunt T-cell effector functions, with this overexpression occurring either on the tumour cells or on other cells within the tumour microenvironment. In contrast, however, tumour-mediated immune evasion is not generally due to overexpression of factors that stimulate T-cell activation ${ }^{27}$.

Therefore one approach that is currently receiving a significant amount of attention is the use of immune checkpoint inhibitors. .Although there was promising data (and FDA approval) for other cancer types ${ }^{28}$, this success has not yet transferred to mesothelioma. There is much focus on blockage of PD-1 (programmed cell death protein 1) and CTLA-4 (cytotoxic T-lymphocyte associated protein 4 ) which are two key negative regulators of the immune system ${ }^{28}$. CTLA-4 is under particular scrutiny due to the fact that ipilimumab, another antibody against it, has been approved for the treatment of melanoma ${ }^{29}$. Immune checkpoint blockade in mesothelioma has been comprehensively reviewed by Marcq and colleagues 30 
Tremelimumab is a monoclonal antibody against CTLA-4 (similar to ipilimumab), which is currently under investigation in clinical trials. Unfortunately, an announcement by AstraZeneca stated that tremelimumab as a monotherapy does not significantly improve survival and that the end point of the study was not reached ${ }^{31}$. At the American Society of Clinical Oncology 2016 meeting, data on the DETERMINE trial (ClinicalTrials.gov identifier NCT01843374) was presented, consisting of 571 patients either untreated or treated with tremelimumab as a second or third-line therapy ${ }^{32}$. Unfortunately again, $81 \%$ of the patients died and there was no statistically significant difference between placebo and treated patients in terms of survival. Ultimately despite the sound scientific justification the use of monoclonal antibodies to immune check point inhibitors is still in its early stages for MPM and thus requires significantly more research (especially randomized clinical trials exploring the impact of these drugs on patients' overall survival) so as to not to misinform those who suffer from this disease, both directly and indirectly.

PD-1, the other primary immune checkpoint marker of interest, has also been under investigation. Pembrolizumab is a monoclonal antibody that blocks the interaction of PD-1 with its ligand, which should lead to a removal of the inhibition of T-cell activity against the cancer. The findings of a clinical trial (KEYNOTE-028) demonstrated that the drug was welltolerated by patients and demonstrated a robust anti-tumour effect in patients with PD-1 ligandpositive MPM ${ }^{33}$. Though promising, and although this highlights potential therapeutic use of immunotherapy, antibodies against other targets have shown less positive results.

The potential of combination immunotherapy against multiple markers has also been assessed. Another PD-1 inhibitor is nivolumab, which again has been approved for treatment of melanoma ${ }^{34}$, though its use in mesothelioma is less well-established. One phase II clinical trial (NCT02716272) is investigating the combination of nivolumab (to inhibit PD-1) with ipilimumab (to inhibit CTLA-4) in mesothelioma, though results are yet to be released. Combination of nivolumab with ipilimumab has already been carried out for other cancer types, providing the basis for this approach ${ }^{35}$. Other clinical trials investigating nivolumab in mesothelioma are NCT02341625, NCT02497508 and NCT02899299, though these are all in the recruitment stage or are ongoing. Combination immunotherapy for melanoma, using nivolumab and ipilimumab, demonstrated high rates of side-effects (with them occurring in $55 \%$ of patients) at grade three or four ${ }^{36}$. This thus also represents an additional factor when investigating the potential of combination immunotherapy in mesothelioma.

Although monoclonal antibody therapy is currently a "hot-topic" as an approach to immunotherapy, there are many other possibilities such as active immunotherapy. Active immunotherapy is the therapeutic approach whereby the aim is the education and activation of the immune system to attack cancer cells. There are different strategies that have been introduced in the clinical setting for MPM and they have raised the attention of medical professionals, being now in the centre of many discussions.

\subsubsection{Active Immunotherapy}

Active immunotherapy may involve therapeutic vaccines, with peptide and cell vaccines being approaches investigated under clinical examination. It has been demonstrated in an early clinical trial that Wilms tumor 1 (WT1), highly expressed in mesothelioma, when used as peptide vaccination induced quantifiable specific immune responses, although no clinical improvement was seen ${ }^{37}$. Two clinical trials are currently ongoing using a derived product of WT1 alone or in combination with chemotherapy (NCT01890980 and NCT01265433). Other approaches include the use of modified bacterial organisms such as L. monocytogenes 
expressing mesothelin, which is overexpressed in mesothelioma and which may be involved in tumour invasion ${ }^{38}$. This cancer vaccine (CRS-207) has been developed to promote an immune response against the tumour-associated antigen mesothelin and is currently part of an ongoing trial (NCT01675765).

Cell vaccines use dendritic cells loaded with tumour-associated antigens; the technique consists of ex vivo manipulation of these cells obtained by peripheral blood precursors and modification with a tumour-specific antigen, and then vaccinating the patient with these cells ${ }^{39}$. There are several clinical trials and a few are completed (NCT00280982 and NCT01241682), whilst others are recruiting or their status is unknown (NCT02395679, NCT02649829 NCT01291420). The phase 1 trial NCT00280982 showed that the vaccine was feasible, welltolerated, and cytotoxic activity against autologous tumour cells was detected in a subgroup of patients ${ }^{40}$.

\subsection{Gene Therapy}

One other mode of therapy which is attracting many researchers is gene therapy, which is a new strategy consisting of genetic manipulation for a therapeutic purpose. It has been shown that several genes are modified in mesothelioma and numerous preclinical studies using different genes and vector systems demonstrated a therapeutic effect with promising results for the clinical setting. Numerous vector systems are available for gene therapy, including (but not limited to) adenoviruses, vaccinia viruses and non-viral options such as antisense oligonucleotide therapy ${ }^{41,42}$.

Adenoviruses represent the most common vector within gene therapy, and have previously been applied in both preclinical and clinical studies in mesothelioma. One study on immunocompetent Fischer rats demonstrated that the herpes simplex virus-thymidine kinase gene when carried by an adenovirus vector resulted in a reduction in tumour burden, though the authors also stated that only small increments in survival were seen ${ }^{43}$. However, a similar approach was later utilised at a Phase I trial, detailed below ${ }^{44}$. The use of vaccinia vectors has also been shown, with vaccinia-vector-cytokine constructs that were intratumourally administered demonstrating tumour regression ${ }^{45}$. Non-viral approaches to gene therapy have been demonstrated to be effective in mesothelioma cell lines, with Smythe and colleagues demonstrating that antisense oligonucleotides against Bcl-xL, an anti-apoptotic member of the Bcl-2 family, promoted apoptosis with or without liposomal delivery ${ }^{42}$.

One form of gene therapy is suicide gene therapy, which uses a virus to deliver a transgene which encodes for a specific enzyme that metabolises prodrugs into toxic metabolites, leading to tumour cell death or "suicide" ${ }^{46}$. A Phase I trial investigated the potential of suicide gene therapy in mesothelioma ${ }^{44}$. The intrapleural administration of this treatment was safe and well tolerated in mesothelioma patients. 34 patients were enrolled but only 2 resulted in long-term durable responses, though as a Phase I study it is too preliminary to draw any conclusions.

As previously mentioned, cytokines represent a potential route through which therapy can be improved. Cytokine gene therapy is a genetic manipulation strategy which uses a viral vector encoding a specific cytokine (such as interleukin-2 [IL-2], IL-12, tumour necrosis factor [TNF] or interferons [INF $-\alpha, \beta$, or $\gamma]$ ) to increase their expression, triggering a direct cytotoxic effect on tumour cells ${ }^{47}$. This approach has the advantage of reducing toxicity and increases the local concentration of these molecules. A phase I study was conducted to evaluate the safety and 
feasibility of single-dose intrapleural IFN- $\beta$ gene transfer using an adenoviral vector (Ad.IFN$\beta$ ) in mesothelioma patients, which showed that it was generally well-tolerated and that transient lymphopenia was the most common side-effect ${ }^{48}$. Antitumour immune responses were seen in $70 \%$ of the patients, whilst $40 \%$ of patients showed a meaningful clinical response (as assessed by disease stability and/or regression). Two clinical trials (Phase I) as gene therapy alone for MPM patients have been under assessment and their status is either ongoing or unknown (NCT00299962, NCT00066404).

Another gene therapy strategy is using genetically modified $\mathrm{T}$ cells engineered with lentiviral or retroviral vectors to produce T-cell receptors that will specifically attack cancer cells ${ }^{49}$. An in vivo study showed that antimesothelin-engineered $\mathrm{T}$-cells recognised mesothelin-expressing cells and induced significant tumour regression ${ }^{50}$. A current phase I study "Autologous Redirected RNA Meso-CIR T Cells" is ongoing (NCT01355965). Another target that can be attractive for gene therapy is fibroblast activation protein (FAP) since it appears to be mainly expressed on the surface of reactive tumour-associated fibroblasts as well cancer cells. Schuberth and colleagues demonstrated that re-directed T cells specific for FAP were cytotoxic towards FAP positive targets in vitro and in vivo ${ }^{51}$, supporting a phase I trial that is currently recruiting to evaluate the safety of a single administration of adoptively transferred FAPspecific re-directed T cells (NCT01722149).

\subsection{Targeted Therapy}

Although the molecular mechanisms involved in MPM are still unclear, in recent years promising pathways have attracted the attention of translational medicine researchers, and as a result several drugs are in the development pipeline and at various stages of preclinical and clinical studies. The main molecules under investigation are responsible for molecular signalling and the aforementioned immune response. Examples of approaches include targeted therapy (direct action against cancer-specific molecules and signalling pathways, resulting in limited nonspecific toxicity), tyrosine-kinase inhibitors, epidermal growth factor receptor (EGFR) targeting, vascular endothelial growth factor (VEGF) targeting and RNA targeting.

Recently small molecule inhibitors, which are able to pass through the membrane and interact with the intracellular domain of receptors and downstream intracellular signalling, have been studied, such as tyrosine kinase inhibitors (TKIs) ${ }^{52}$.

\subsubsection{Tyrosine Kinase Inhibitors Against EGFR}

TKIs are primarily effective in the targeted treatment of various malignancies and most of them act as competitor with the ATP binding site of the catalytic domain of numerous tyrosine kinases ${ }^{53}$. TKIs are oral drugs with an established safety profile and can be efficiently combined with other forms of treatment including chemotherapy or radiation therapy ${ }^{54}$. Numerous TKIs have showed an effective antitumor activity in various cancer types and have been approved for the clinic. TKIs are currently under investigation in mesothelioma.

EGFR is one such target of TKIs, which is involved in downstream signalling pathways related to oncogenes and activates the RAS/RAF/MAPK cascade which plays a role in cell proliferation, metastasis, and invasion ${ }^{55}$ and the PI3KCA/AKT/mTOR pathway, which determines the inhibition of apoptosis ${ }^{56}$. Therefore, abnormal EGFR signalling contributes to the development of a malignant phenotype in several varieties of epithelial cancers as well as MPM $^{57,58}$. It has been reported that EGFR is overexpressed in $60-70 \%$ of MPM tissue 
specimens ${ }^{59}$ and inhibition of EGFR-dependent signalling pathways in mesothelioma cell lines also causes reduced cell survival ${ }^{57}$. Gefinitib (ZD1839, Iressa), a potent TKI has been studied in a phase II study in 43 patients with unresectable disease but it was not active despite the fact that in $97 \%$ of patients EGFR was overexpressed ${ }^{60}$. Another EGFR TKI, erlotinib (OSI-774, Tarceva) was used in a phase II trial in previously untreated patients with MPM but singleagent erlotinib was not effective ${ }^{61}$. Another clinical trial of erlotinib (Tarceva) plus bevacizumab (Avastin) in previously treated patients with MPM did not show an effective response ${ }^{62}$. One of the major obstacles for the use of TKIs against EGFR in mesothelioma is that although EGFR is overexpressed in the majority of MPM patients, this overexpression does not correlate with clinical outcomes following use of TKIs ${ }^{63}$. Elucidation for clinical failure may be that mutations analysed in patients with other malignancies may not be different from MPM patients ${ }^{59}$, or alternatively the frequency of mutation may be too low in mesothelioma patients ${ }^{64}$, resulting in the lack of clinical response in non-selected patients.

Another class of EGFR inhibitors is anti-EGFR monoclonal antibodies (mABs), which interact with the extracellular domain of EGFR, competing with EGF ligand. Cetumixab (Ertibux) showed a therapeutic efficacy on blocking cell growth in MPM cell lines and mouse models ${ }^{65}$ and a phase II study with cetuximab in combination with cisplatin or carboplatin/pemetrexed as first line treatment has been completed, though no study results have yet been posted (NCT00996567).

\subsubsection{Tyrosine Kinase Inhibitors Against VEGF}

Neoangiogenesis is a hallmark of cancer which contributes to tumour growth and metastatic dissemination ${ }^{66}$. It is well-established that vascular VEGF is the most powerful angiogenic promoter, released by several malignancies including MPM ${ }^{67,68}$. The role of VEGF has been detected in MPM in studies, showing high levels (detected by immunohistochemistry) in the tissue specimens of patients with MPM ${ }^{69}$ and as free circulating molecules ${ }^{70}$. All this evidence has highlighted that an anti-VEFG therapy could have a therapeutic effect in MPM patients.

VEGF or VEGF receptor (VEGFR) inhibitors have been used in several clinical trials as a single therapy or in combination with chemotherapy for MPM patients as reported in Table 1. Bevacizumab (Avastin), a humanized monoclonal antibody against VEGF, the most potent growth factor involved in tumour angiogenesis, was approved in the EU in 2005 for the treatment of carcinoma, non-small-cell lung cancer, colorectal cancer, carcinoma, renal cell cancer, and ovarian cancers ${ }^{71-74}$. Bevacizumab has been evaluated as first-line treatment in a phase II clinical trial with cisplatin and pemetrexed in patients with advanced mesothelioma. The trial failed to achieve the primary endpoint ${ }^{75}$. A phase III multicentre, randomized, controlled study of bevacizumab in addition to cisplatin and pemetrexed in untreated mesothelioma patients has also been carried out ${ }^{76}$. The overall survival was statistically significantly longer in patients treated with the triple therapy regimen than cisplatin and pemetrexed. Though statistically significant the difference was only 2.7 months, highlighting the need for further research. The majority of VEGFR tyrosine kinase inhibitors such as vatalanib (PTK787/ZK 222584), sorafenib, sunitinib, imatinib, and cediranib (AZD2171) have been studied in MPM and have shown limited or absent levels of activity, resulting in a lack of clinical benefits ${ }^{77-82}$. Nintedanib (BIBF 1120), an oral potent triple angiokinase inhibitor, is under investigation in two Phase II clinical trials as single treatment and in combination with pemetrexed and cisplatin followed by maintenance nintedanib compared with chemotherapy alone in patients with unresectable MPM (NCT02568449, NCT01907100, respectively). 


\subsubsection{Histone Deacetylase (HDAC) Inhibition}

Another class of drugs that are under investigation as targeted therapy include vorinostat and belinostat, drugs with inhibitory activity against histone deacetylase (HDAC) enzymes, which control gene expression through histone modifications ${ }^{83}$ and it has been demonstrated that HDAC inhibitors promote susceptibility of mesothelioma cell lines to tumour necrosis factorrelated apoptosis-inducing ligand (TRAIL) ${ }^{84}$. Vorinostat, one of the common HDAC inhibitors, has shown activity against mesothelioma in phase I trials ${ }^{85}$. A phase III, multicentre trial (VINTAGE-014) of vorinostat versus placebo as a second-line or third-line therapy failed to show an improved overall survival ${ }^{86}$. A phase II trial with Belinostat (PXD 101) as secondline therapy in advanced mesothelioma did not show clinical activity ${ }^{87}$.

\subsubsection{Focal Adhesion Kinase (FAK) Inhibition}

One the most frequently mutated tumour suppressor genes detected in mesothelioma cells is NF2, which inactivates merlin (the protein product of the NF2 gene) and results in an increase of the activity of focal adhesion kinase (FAK). FAK is a cytoplasmic protein, a tyrosine kinase that is involved in cell proliferation, survival, migration, invasion and cancer stem cell (CSC) renewal ${ }^{88}$. A study reported that FAK was overexpressed in mesothelioma cell lines and implicated in promoting invasiveness ${ }^{89}$. Defactinib (VS-6063) is a highly potent, selective FAK inhibitor. A phase II randomized multicenter trial (COMMAND) of defactinib in previously treated MPM was performed but the study has been terminated to lack of efficacy (NCT01870609). Recently another FAK inhibitor (GSK2256098), has been tested in a phase I study in patients with advanced cancer, including mesothelioma patients ${ }^{90}$. The initial pharmacologic and pharmacokinetic studies showed an acceptable and safe profile in patients with mesothelioma, in particular those harbouring merlin loss ${ }^{90}$. In addition, another phase I trial has been completed, though no study results have been posted yet (NCT01938443). This study investigated the effect of dose escalation of GSK2256098 in combination with trametinib, a mitogen-activated protein kinase (MEK) inhibitor in patients with advanced solid tumours, including mesothelioma.

\subsubsection{Other Targeted Therapies}

Bortezomib is a selective inhibitor that acts via downregulation of nuclear factor- $\mathrm{kB}$ and thus promotes apoptosis. A phase II study investigating the activity of Bortezomib as first-line and second-line therapy in MPM patients demonstrated a lack of clinical activity and thus did not warrant further investigations ${ }^{91}$.

In addition to the above is BNC105P, an inhibitor that selectively blocks tubulin, which through polymerisation promotes cancer cell proliferation. It showed effective activity in preclinical and phase I studies ${ }^{92}$. A phase II study with BNC105P investigated its efficacy and safety as second line therapy in MPM but the response was insufficient to justify further studies ${ }^{92}$.

Cixutumumab (Agent IMC-A12) is a humanized antibody against insulin growth factor-I receptor (IGF-IR), which in cooperation with its ligands (IGF-I) play a role in cell proliferation, invasion, and metastasis though IGF signalling pathway ${ }^{93}$. A study demonstrated that cixutumumab decreased the growth of mesothelioma compared to the control group in in vivo models ${ }^{93}$. A phase II clinical trial of cixutumumab in previously treated patients with MPM is currently ongoing (NCT01160458). 
Another example of targeted therapy which involves RNA as a therapeutic target is ranpirnase which targets tRNA and is able to promote impaired protein synthesis and cell cycle arrest, showed that it has an antitumor activity ${ }^{94}$. In mesothelioma cell lines, ranpirnase inhibited cell growth, both in vitro and in vivo ${ }^{95}$. A phase II study with ranpirnase as single drug in untreated patients has showed that ranpirnase may have an activity and a tolerable toxicity profile and phase III trial of ranpirnase was conducted in comparison with single-agent doxorubicin showing no significant difference (only 2 months; 11.3 vs 9.1 months) ${ }^{94}$. Another phase III randomized study was conducted with ONCONASE (ranpirnase) plus doxorubicin versus doxorubicin alone ${ }^{94}$. The clinical outcomes, however, are not yet available.

Human tumour necrosis factor-alpha (hTNF- $\alpha$ ), has an antitumor activity in many solid tumours, including malignant mesothelioma ${ }^{96}$. However, several studies have shown that administration of hTNF- $\alpha$ lead to a toxic effect, and therefore NGR-hTNF- $\alpha$ has been developed as a fusion protein with a cyclic tumour-homing peptide (CNGRCG), asparagineglycine-arginine and tested in a phase II as maintenance treatment in patients with advanced MPM. At the moment this study is recruiting participants (NCT01358084). NGR015 is a randomized double-blind phase III study of NGR-hTNF- $\alpha$ plus Best Investigator's Choice (BIC, a choice of different chemotherapy drugs) versus placebo plus BIC as second line therapy in patients with advanced MPM is also ongoing but not recruiting participants (NCT01098266).

GC1008 is an anti-TGF $\beta$ antibody. TGF $\beta$ is involved in tumour progression due to its abilities to stimulate vessel formation, modify the stromal environment, and, mainly, promote local and systemic immunosuppression ${ }^{97}$. Additional investigational strategies evaluated the role of heat shock protein 90 (HSP90) inhibitor (ganetespib), enhancer of zeste homolog 2 (EZH2) inhibitor (Tazemetostat), inhibitor of the MET receptor tyrosine kinase (Tivantinib), Cancer Stem Cell (CSC) inhibitor (Napabucasin/BBI608) and TargomiRs (a mimic microRNA treatment). These trials are all active trials and some of them are recruiting (Table 1).

\subsection{Conclusions}

The lack of effective treatment for mesothelioma highlights an urgent need to develop novel therapeutics. It is surprising that treatments which are proven effective for other cancer types such as tyrosine kinase inhibitors do not show clinical benefit for mesothelioma. Although immunotherapy has been successfully applied to melanoma, immune checkpoint blockade requires more research before its application to treat mesothelioma due to recent clinical trials setbacks. Similarly, the failure of many clinical trials for other promising therapies remains problematic. Isolating the driving issues behind the failure of these treatments to show significant effects may assist in resolving this long-standing issue.

Possible causes for failure of these therapies at the clinical level are numerous. Immunotherapy, despite high hopes for approaches such as immune checkpoint blockade, has generally not resulted in a clinical benefit for mesothelioma. Primarily, it has been shown useful for melanoma and side-effects have been observed ${ }^{28}$. Resistance to immune checkpoint inhibition has been indicated to arise through stromal cells mediated by chemokine (C-X-C motif) ligand 12 (CXCL12) which promoted immune evasion, based on model of pancreatic ductal adenocarcinoma ${ }^{98}$. FAP has been shown to be expressed on tumour-associated fibroblasts and cancer cells, and use of human CD8+ T cells transduced with anti-FAP demonstrated growth inhibition of FAP-positive tumour cells ${ }^{51}$, thus providing further evidence for the role of the stroma. It has been argued that once the toxicity of the immune checkpoint inhibitors reaches 
acceptable levels approaches such as combination checkpoint therapy could be employed, or their role as adjuvant therapy considered ${ }^{29}$. However, further research is required prior to the clinic for immune checkpoint blockade in mesothelioma.

Mesothelioma is a cancer characterised by a low mutational load, which may represent an explanation for the failure of TKIs. For instance, it has been demonstrated that in peritoneal mesothelioma, patients lack the EGFR mutations that would render them sensitive to TKIs ${ }^{99}$. Similarly, in a patient cohort $(\mathrm{n}=38)$ of pleural and peritoneal mesothelioma, EGFR mutations were detected only in six $(16 \%)$ patients ${ }^{100}$. An additional factor that may contribute towards therapy failure is the hypoxic environment that defines mesothelioma. It has been shown that hypoxia induces NOTCH1 whose inhibition promoted apoptosis in mesothelioma cells ${ }^{101}$. Furthermore, hypoxia has also been shown to promote motility and invasiveness of MPM cells 102. Thus, characterisation of the effects of hypoxia on the tumour cell's gene expression profile could represent a route through which therapies could be improved.

Ultimately further research is required to improve therapeutic outcomes. A significant effort has been employed to discover new therapies for mesothelioma yet this cancer remains difficult to treat. It is possible that a focus on different pathways may yield improved outcomes, as expanded upon in the Expert Opinion.

\section{Expert Opinion}

Despite the attempts to find new therapeutic routes, MPM is still an "orphan" disease and the lack of treatment really improving the prognosis of these tumours is urging us to take action.

There is no doubt that any achievement for this tumour should be based on a better understanding of the genetic and biological mechanisms underlying its carcinogenesis and progression. The inflammatory microenvironment (including the stromal cells), the low mutational load, along with the marked immune suppression are just some of the features that pose as difficult hurdles to the identification of new treatments.

The asbestos fibre-dependent inflammation affects the immune response, whereas the low mutational load of MPM cells does not allow the expression on a sufficient "battery" of neoantigens necessary to trigger a robust immune reaction. On the other hand, the role of tumour cell proliferation and neoangiogenesis looks to be significantly less relevant than in other tumours if one considers the lack of efficacy or the modest activity of the treatment of this tumour with TKIs or anti-angiogenic agents respectively. The absence of driving genes and the onset of selective pressure exerted by TKIs provide a possible explanation of the failure of these therapies for MPM and prompt us to rethink their use i.e. combined treatments and alternative pathways of growth.

Therefore it seems clear that the shortcut of treating MPM with drugs because they have shown a certain degree of activity in other tumour is likely not to be the best option.

As opposite it is imperative to explore new avenues offered by the mechanism that MPM cells exploit to survive within the hostile microenvironment and with particular attention to the type of nutrients and their cell machinery. With regard to this other authors have already shown how MPM is an extremely hypoxic tumour ${ }^{101,103,104}$ and we have already demonstrated how MPM cell metabolisms is highly dependent on glycolysis, providing the evidence for targeting this metabolic reprogramming ${ }^{105}$. 
Eventually, if one considers the current front line therapy for MPM is the combination treatment of chemotherapy plus antiangiogenic agents ${ }^{76}$ improves the survival only by three months compared to chemotherapy alone, it is clear that more research is the first mandatory step in the direction of more effective treatments for MPM.

\section{Highlights Box}

1) Current treatments for mesothelioma do not significantly enhance survival

2) Despite the application of immunotherapy in melanoma treatment, challenges remain for this therapy to be effective for mesothelioma

3) The use of targeted therapy may lead to improved clinical outcomes, however the presence of protein overexpression and use of inhibitors does not always follow through at the clinical level

4) Although neoangiogenesis and VEGF expression are undoubtedly a feature of mesothelioma, anti-VEGF/R treatments do not appear to have a clinical benefit, excepting triple combination therapy with cisplatin and pemetrexed which extends survival by 2.7 months

5) Improved understanding of the basic mechanisms mesothelioma cells use to survive in their hostile environment (with particular attention on nutrition and cellular machinery) could lead to new development pipelines and therapeutic possibilities 
Table 1: Summary of completed and ongoing clinical trials in mesothelioma

\begin{tabular}{|c|c|c|c|c|}
\hline Intervention & Clinical trial & $\mathrm{N}$ patients & Phase & Status \\
\hline \multicolumn{5}{|l|}{$\begin{array}{c}\text { Immunotherapy } \\
\text { strategies }\end{array}$} \\
\hline $\begin{array}{l}\text { Immune checkp } \\
\text { blockade }\end{array}$ & & & & \\
\hline Pembrolizumab & NCT02054806 & 477 & I & ongoing \\
\hline Nivolumab & $\begin{array}{l}\frac{\text { NCT02716272 }}{\text { NCT02341625 }} \\
\text { NCT02497508 } \\
\text { NCT02899299 }\end{array}$ & $\begin{array}{c}125 \\
407^{*} \\
33 \\
600^{*}\end{array}$ & $\begin{array}{c}\text { II } \\
\text { I/II } \\
\text { II } \\
\text { III }\end{array}$ & $\begin{array}{l}\text { ongoing } \\
\text { recruiting } \\
\text { ongoing } \\
\text { recruiting }\end{array}$ \\
\hline Tremelimumab & NCT01843374 & 658 & II & ongoing \\
\hline
\end{tabular}

Wilms Tumor-1 (WT1)

vaccine

\begin{tabular}{clccc} 
WT-1-vaccine & NCT01890980 & $60^{*}$ & II & $\begin{array}{l}\text { ongoing } \\
\text { ongoing }\end{array}$ \\
\cline { 2 - 3 } & $\underline{\text { NCT01265433 }}$ & 31 & II & ontanide
\end{tabular}

Anti mesothelin

vaccine

$\begin{array}{lllll}\text { CRS-207 } & \text { NCT01675765 } & 60 & \text { I } & \text { ongoing }\end{array}$

\section{Dendritic Cell-based vaccine}

$\begin{array}{clccc}\begin{array}{c}\text { Tumour lysate-loaded } \\ \text { autologous dendritic }\end{array} & \text { NCT00280982 } & 10 & \text { I } & \text { completed } \\ \text { cells } & \underline{\text { NCT01241682 }} & 10 & \text { I } & \text { completed } \\ & \underline{\text { NCT02395679 }} & 9^{*} & \text { I } & \text { unknown } \\ & \underline{\text { NCT02649829 }} & 20^{*} & \text { I/II } & \text { recruiting } \\ & \underline{\text { NCT01291420 }} & 10^{*} & \text { I/II } & \text { unknown }\end{array}$


Adenoviral-mediated

IFN- $\beta$

$\begin{array}{llccc}\text { BG00001 } & \text { NCT00299962 } & 18^{*} & \text { I } & \text { ongoing } \\ \text { NCT00066404 } & - & \text { I } & \text { unknown }\end{array}$

\section{Adoptive T Cell \\ Immunotherapy}

$\begin{array}{lllll}\text { Autologous T cells } & \text { NCT01355965 } & 18 & \text { I } & \text { ongoing }\end{array}$

Adoptive Transfer of re- $\underline{\text { NCT01722149 }} \quad 6^{*} \quad$ I r recruiting directed T cells

Tyrosine kinase inhibitors

\section{EGF inhibitors}

Gefinitib (ZD1839, $\quad$ NCT00025207 40 Iressa)

Erlotinib ( OSI 774,Tarceva)

NCT00039182 55

$55 \quad$ II

II completed

NCT00137826 37

II

completed

Cetuximab (Ertibux)

NCT00996567 22

II

completed

Anti-angiogensis

inhbitors

Vatalanib

NCT00053885

47

II

completed

Sorafenib

NCT00794859

$54^{*}$

II

unknown

Sunitinib

NCT00392444

39

II

completed

Imatinib (Glicev)

NCT00402766

19

NCT02303899

22

I

completed

ongoing 


\begin{tabular}{|c|c|c|c|c|}
\hline Cediranib (AZD2171) & $\frac{\frac{\text { NCT00243074 }}{\text { NCT00243074 }}}{\text { NCT01064648 }}$ & $\begin{array}{c}54 \\
54 \\
116^{*}\end{array}$ & $\begin{array}{c}\text { II } \\
\text { II } \\
\text { I/II }\end{array}$ & $\begin{array}{l}\text { completed } \\
\text { completed } \\
\text { ongoing }\end{array}$ \\
\hline Nintedanib & $\begin{array}{l}\frac{\text { NCT02568449 }}{\text { NCT02863055 }} \\
\text { NCT01907100 } \\
\end{array}$ & $\begin{array}{l}55^{*} \\
116^{*} \\
537^{*}\end{array}$ & $\begin{array}{l}\text { II } \\
\text { II } \\
\text { III }\end{array}$ & $\begin{array}{l}\text { recruiting not y } \\
\text { recruiting } \\
\text { recruiting }\end{array}$ \\
\hline Bevacizumab & $\frac{\text { NCT00295503 }}{\text { NCT00651456 }}$ & $\begin{array}{c}53 \\
448\end{array}$ & $\begin{array}{l}\text { II } \\
\text { III }\end{array}$ & $\begin{array}{l}\text { completed } \\
\text { completed }\end{array}$ \\
\hline
\end{tabular}

Histone deacetylase inhibitors

Vorinostat (MK-0683) $\quad \underline{\text { NCT00128102 }} 662 \quad$ III $\quad$ completed

$\begin{array}{lllll}\text { Belinostat } & \text { NCT00365053 } & 13 & \text { II } & \text { completed }\end{array}$

FAK inhibitors

Defactinib (VS-6063) $\quad \underline{\text { NCT01870609 }} 344 \quad$ II $\quad$ terminated

$\begin{array}{lllll}\text { GSK2256098 } & \text { NCT01938443 } & 34 & \text { I } & \text { completed }\end{array}$

NF-kB pathway

inhibitor

$\begin{array}{lllll}\text { Bortezomib } & \text { NCT00513877 } & 33 & \text { II } & \text { completed }\end{array}$

IGF-IR inhibitor

$\begin{array}{lllll}\text { Cixutumumab } & \text { NCT01160458 } & 20 & \text { II } & \text { ongoing }\end{array}$

\section{Cytotoxic RNase}

$\begin{array}{llll}\text { Ranpirnase } \quad \underline{\text { NCT00003034 }} 300 \quad \text { III } & \text { unknown }\end{array}$

(ONCONASE) 
A recombinant protein

hTNF- $\alpha$ fused with a

peptide

$\begin{array}{lllll}\text { NGR-hTNF } & \underline{\text { NCT01358084 }} & 100 * & \text { II } & \begin{array}{c}\text { recruiting } \\ \text { ongoing }\end{array}\end{array}$

\section{Anti-TGF Monoclonal \\ Antibody}

$\begin{array}{lllll}\text { GC1008 } & \text { NCT01112293 } & 14 & \text { II } & \text { completed }\end{array}$

\section{HSP90 inhibitor}
Ganetespib
$\underline{\text { NCT01590160 }}$
27
I/II
ongoing

EZH2 inhibitor

Tazemetostat

NCT02860286 67

$67^{*} \quad$ II

II recruiting

$\underline{\underline{\text { NCT02875548 }} 300^{*} \quad \text { II } \quad \text { recruiting }}$

MET receptor tyrosine

kinase inhibitor

Tivantinib

NCT01861301 18

$18 \quad$ II

II

terminated

$\begin{array}{llll}\text { NCT02049060 } & 31 \quad \text { I/II } & \text { ongoing }\end{array}$

CSC inhibitor

BBI608

NCT02347917

24

I/II

ongoing

Mimic microRNA

treatment

$\begin{array}{lllll}\text { TargomiRs } & \text { NCT02369198 } & 27 & \text { I } & \text { completed }\end{array}$

* Estimated number of participants 


\section{Conflict of Interest Statement}

All authors have nothing to disclose.

\section{Table 1 Legend:}

A detailed overview of numerous clinical trials across numerous therapeutic approaches in mesothelioma. Targets under investigation and the specific drug or inhibitor used are detailed, as is a hyperlink of the ClinicalTrials.gov identifier, in addition to the number of patients enrolled, the phase of the trial, and its current status.

\section{Figure 1 Legend:}

Overview of different therapeutic strategies. Closed arrows represent inhibition whilst directed arrows represent activation or stimulation. 


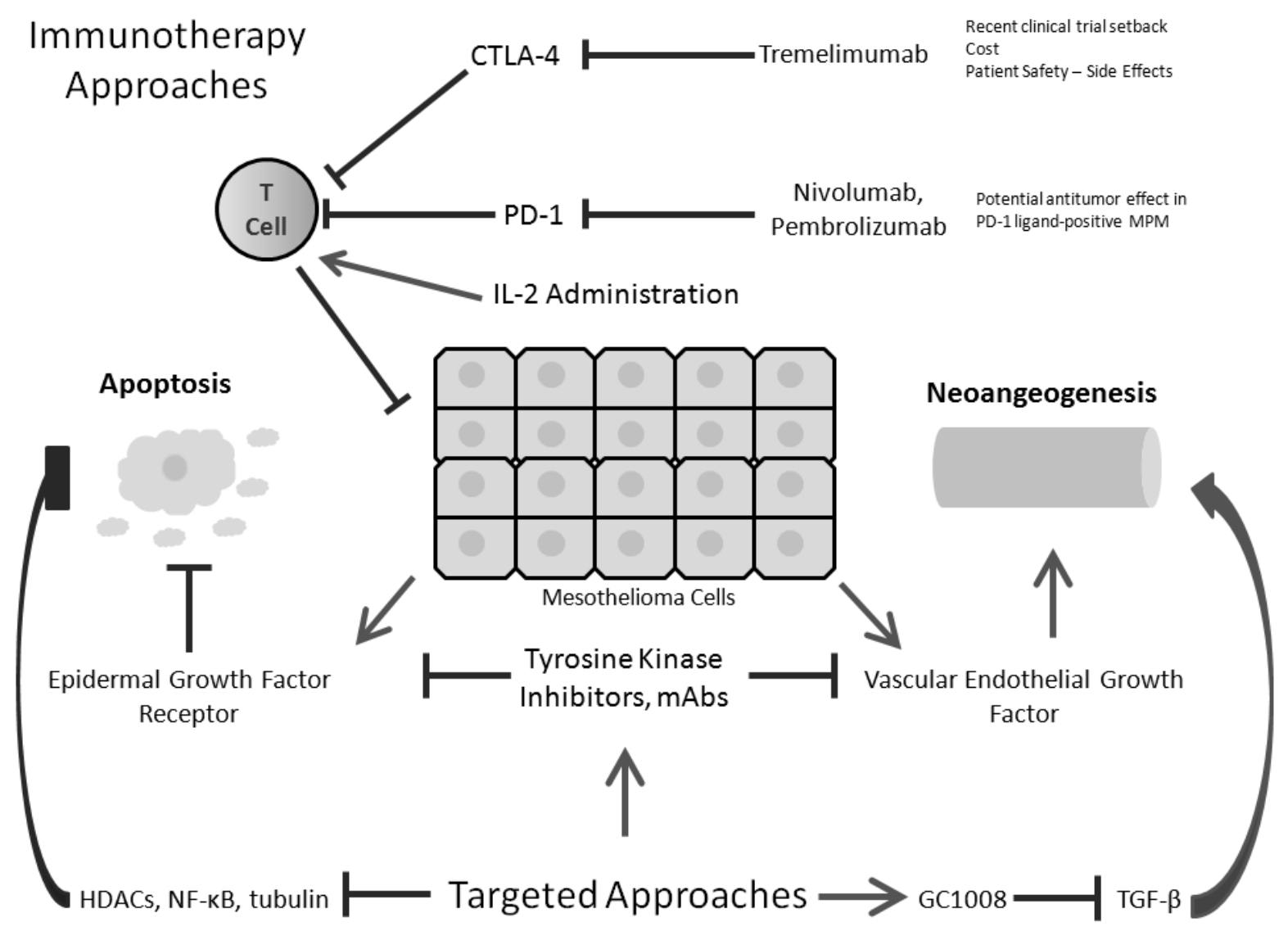

Figure 1: Overview of different therapeutic strategies. Closed arrows represent inhibition whilst directed arrows represent activation or stimulation. 


\section{References}

1. Hispan P, Pascual JC, Gonzalez I, Bravo D, Peiro G. Cutaneous Metastases From Malignant Mesothelioma of the Tunica Vaginalis Testis. The American Journal of dermatopathology 2016 Mar;38(3):222-5.

2. Segura-Gonzalez M, Urias-Rocha J, Castelan-Pedraza J. Malignant Mesothelioma of the Tunica Vaginalis: A Rare Neoplasm--Case Report and Literature Review. Clinical genitourinary cancer 2015 Dec;13(6):e401-5.

3. Ismail-Khan R, Robinson LA, Williams CC, Jr., Garrett CR, Bepler G, Simon GR. Malignant pleural mesothelioma: a comprehensive review. Cancer control : journal of the Moffitt Cancer Center 2006 Oct;13(4):255-63.

**Ismail-Khan and colleagues have written a highly detailed article on mesothelioma incorporating various information such as stages, treatments, and clinical features.

4. Peto J, Decarli A, La Vecchia C, Levi F, Negri E. The European mesothelioma epidemic. British journal of cancer 1999 Feb;79(3-4):666-72.

5. Neumann V, Loseke S, Nowak D, Herth FJ, Tannapfel A. Malignant pleural mesothelioma: incidence, etiology, diagnosis, treatment, and occupational health. Deutsches Arzteblatt international 2013 May;110(18):319-26.

6. Roe OD, Stella GM. Malignant pleural mesothelioma: history, controversy and future of a manmade epidemic. European respiratory review : an official journal of the European Respiratory Society 2015 Mar;24(135):115-31.

7. Mutti L. Malignant pleural mesothelioma: new ideas needed. Lung Cancer Management 2015 2015/10/01;4(5):201-03.

8. Guazzelli A, Hussain M, Krstic-Demonacos M, Mutti L. Tremelimumab for the treatment of malignant mesothelioma. Expert opinion on biological therapy 2015;15(12):1819-29.

9. Belli C, Fennell D, Giovannini M, Gaudino G, Mutti L. Malignant pleural mesothelioma: current treatments and emerging drugs. Expert opinion on emerging drugs 2009 Sep;14(3):423-37.

10. Sugarbaker DJ, Wolf AS. Surgery for malignant pleural mesothelioma. Expert review of respiratory medicine 2010 Jun;4(3):363-72.

11. Porpodis K, Zarogoulidis P, Boutsikou E, Papaioannou A, Machairiotis N, Tsakiridis $\mathrm{K}$, et al. Malignant pleural mesothelioma: current and future perspectives. Journal of thoracic disease 2013 Sep;5 Suppl 4:S397-406.

12. Flores RM, Zakowski M, Venkatraman E, Krug L, Rosenzweig K, Dycoco J, et al. Prognostic factors in the treatment of malignant pleural mesothelioma at a large tertiary referral center. Journal of thoracic oncology : official publication of the International Association for the Study of Lung Cancer 2007 Oct;2(10):957-65. 
13. Papaspyros S, Papaspyros S. Surgical Management of Malignant Pleural Mesothelioma: Impact of Surgery on Survival and Quality of Life-Relation to Chemotherapy, Radiotherapy, and Alternative Therapies. ISRN Surgery 2014 02/03

11/10/received

12/12/accepted;2014:817203.

14. Formenti SC, Demaria S. Combining radiotherapy and cancer immunotherapy: a paradigm shift. Journal of the National Cancer Institute 2013 Feb 20;105(4):256-65.

15. Remon J, Reguart N, Corral J, Lianes P. Malignant pleural mesothelioma: new hope in the horizon with novel therapeutic strategies. Cancer treatment reviews 2015 Jan;41(1):2734.

16. Pinton G, Manente AG, Tavian D, Moro L, Mutti L. Therapies currently in Phase II trials for malignant pleural mesothelioma. Expert opinion on investigational drugs 2013 Oct;22(10):1255-63.

17. Bertino P, Porta C, Barbone D, Germano S, Busacca S, Pinato S, et al. Preliminary data suggestive of a novel translational approach to mesothelioma treatment: imatinib mesylate with gemcitabine or pemetrexed. Thorax 2007 Aug;62(8):690-5.

18. Wong RM, Ianculescu I, Sharma S, Gage DL, Olevsky OM, Kotova S, et al. Immunotherapy for malignant pleural mesothelioma. Current status and future prospects. American journal of respiratory cell and molecular biology 2014 May;50(5):870-5.

19. Vogelzang NJ, Rusthoven JJ, Symanowski J, Denham C, Kaukel E, Ruffie P, et al. Phase III study of pemetrexed in combination with cisplatin versus cisplatin alone in patients with malignant pleural mesothelioma. Journal of clinical oncology : official journal of the American Society of Clinical Oncology 2003 Jul 15;21(14):2636-44.

20. Leigh RA, Webster I. Lymphocytic infiltration of pleural mesothelioma and its significance for survival. South African medical journal = Suid-Afrikaanse tydskrif vir geneeskunde 1982 Jun 26;61(26):1007-9.

21. Grégoire M. What's the place of immunotherapy in malignant mesothelioma treatments? Cell Adhesion \& Migration 2010 Jan-Mar;4(1):153-61.

** Comprehensive review by Grégoire regarding immunotherapy in mesothelioma

22. Lew F, Tsang P, Holland JF, Warner N, Selikoff IJ, Bekesi JG. High frequency of immune dysfunctions in asbestos workers and in patients with malignant mesothelioma. Journal of clinical immunology 1986 May;6(3):225-33.

23. DeLong P, Carroll RG, Henry AC, Tanaka T, Ahmad S, Leibowitz MS, et al. Regulatory T cells and cytokines in malignant pleural effusions secondary to mesothelioma and carcinoma. Cancer biology \& therapy 2005 Mar;4(3):342-6.

24. Hegmans JP, Hemmes A, Aerts JG, Hoogsteden HC, Lambrecht BN. Immunotherapy of murine malignant mesothelioma using tumor lysate-pulsed dendritic cells. American journal of respiratory and critical care medicine 2005 May 15;171(10):1168-77. 
25. Astoul P, Picat-Joossen D, Viallat JR, Boutin C. Intrapleural administration of interleukin-2 for the treatment of patients with malignant pleural mesothelioma: a Phase II study. Cancer 1998 Nov 15;83(10):2099-104.

26. Haas AR, Sterman DH. Malignant Pleural Mesothelioma: Update on Treatment Options with a Focus on Novel Therapies. Clinics in chest medicine 2013 01/17;34(1):99111.

27. Pardoll DM. The blockade of immune checkpoints in cancer immunotherapy. Nature reviews Cancer 2012 Mar 22;12(4):252-64.

* Pardoll has written a useful overview of immune checkpoint blockade for cancer in general

28. Bakker E, Qattan M, Mutti L, Demonacos C, Krstic-Demonacos M. The role of microenvironment and immunity in drug response in leukemia. Biochimica et biophysica acta 2016 Mar;1863(3):414-26.

29. Guazzelli A, Bakker E, Krstic-Demonacos M, Lisanti MP, Sotgia F, Mutti L. AntiCTLA-4 therapy for malignant mesothelioma. Immunotherapy 2017 Mar;9(3):273-80.

30. Marcq E, Pauwels P, van Meerbeeck JP, Smits EL. Targeting immune checkpoints: New opportunity for mesothelioma treatment? Cancer treatment reviews 2015 Dec;41(10):914-24.

31. AstraZeneca. AstraZeneca reports top-line result of tremelimumab monotherapy trial in mesothelioma. 2016 [cited; Available from: https://www.astrazeneca.com/mediacentre/press-releases/2016/astrazeneca-reports-top-line-result-of-tremelimumabmonotherapy-trial-in-mesothelioma-29022016.html

32. Kindler HL, Scherpereel A, Calabrò L, Aerts J, Perez SC, Bearz A, et al. Tremelimumab as second- or third-line treatment of unresectable malignant mesothelioma (MM): Results from the global, double-blind, placebo-controlled DETERMINE study. 2016 ASCO Annual Meeting. Chicago, USA 2016.

33. Alley EW, Molife LR, Santoro A, Beckey K, Yuan S, Cheng JD, et al. Abstract CT103: Clinical safety and efficacy of pembrolizumab (MK-3475) in patients with malignant pleural mesothelioma: Preliminary results from KEYNOTE-028. Cancer research 2015;75(15 Supplement):CT103-CT03.

34. Hamanishi J, Mandai M, Matsumura N, Abiko K, Baba T, Konishi I. PD-1/PD-L1 blockade in cancer treatment: perspectives and issues. International Journal of Clinical Oncology 2016;21(3):462-73.

35. Wolchok JD, Kluger H, Callahan MK, Postow MA, Rizvi NA, Lesokhin AM, et al. Nivolumab plus Ipilimumab in Advanced Melanoma. New England Journal of Medicine 2013;369(2):122-33.

36. Doyle C. Combination Immunotherapy Superior to Monotherapy in Patients with Melanoma. American Health \& Drug Benefits 2015;8(Spec Issue):41-41. 
37. Krug LM, Dao T, Brown AB, Maslak P, Travis W, Bekele S, et al. WT1 peptide vaccinations induce CD4 and CD8 $\mathrm{T}$ cell immune responses in patients with mesothelioma and non-small cell lung cancer. Cancer Immunol Immun 2010 Oct;59(10):1467-79.

38. Cristaudo A, Foddis R, Vivaldi A, Guglielmi G, Dipalma N, Filiberti R, et al. Clinical significance of serum mesothelin in patients with mesothelioma and lung cancer. Clinical cancer research : an official journal of the American Association for Cancer Research 2007 Sep 01;13(17):5076-81.

39. Gilboa E. DC-based cancer vaccines. J Clin Invest 2007 May;117(5):1195-203.

* Detailed article by Gilboa on dendritic cell-based cancer vaccines

40. Hegmans JP, Veltman JD, Lambers ME, de Vries IJM, Figdor CG, Hendricks RW, et al. Consolidative Dendritic Cell-based Immunotherapy Elicits Cytotoxicity against Malignant Mesothelioma. American journal of respiratory and critical care medicine 2010 Jun 15;181(12):1383-90.

41. van der Most RG, Robinson BWS, Nelson DJ. Gene therapy for malignant mesothelioma: beyond the infant years. Cancer Gene Ther 2006 01/27/online;13(10):897904.

42. Smythe WR, Mohuiddin I, Ozveran M, Cao XX. Antisense therapy for malignant mesothelioma with oligonucleotides targeting the bcl-xl gene product. The Journal of thoracic and cardiovascular surgery 2002 Jun;123(6):1191-8.

43. Elshami AA, Kucharczuk JC, Zhang HB, Smythe WR, Hwang HC, Litzky LA, et al. Treatment of pleural mesothelioma in an immunocompetent rat model utilizing adenoviral transfer of the herpes simplex virus thymidine kinase gene. Hum Gene Ther 1996 Jan 20;7(2):141-8.

44. Sterman DH, Recio A, Vachani A, Sun J, Cheung L, DeLong P, et al. Long-term follow-up of patients with malignant pleural mesothelioma receiving high-dose adenovirus herpes simplex thymidine kinase/ganciclovir suicide gene therapy. Clinical Cancer Research 2005 Oct 15;11(20):7444-53.

45. Jackaman C, Nelson DJ. Cytokine-armed vaccinia virus infects the mesothelioma tumor microenvironment to overcome immune tolerance and mediate tumor resolution. Cancer Gene Ther 2010 06//print; 17(6):429-40.

46. Zarogoulidis P, Darwiche K, Sakkas A, Yarmus L, Huang H, Li Q, et al. Suicide Gene Therapy for Cancer - Current Strategies. Journal of genetic syndrome \& gene therapy 2013;4:16849.

47. Qian C, Liu XY, Prieto J. Therapy of cancer by cytokines mediated by gene therapy approach. Cell Res 2006 Feb;16(2):182-88.

48. Sterman DH, Kanther M. A phase I clinical trial of single-dose intrapleural IFN-beta gene transfer for malignant pleural mesothelioma and metastatic pleural effusions: High rate of antitumor immune responses (vol 13, pg 4456, 2007). Clinical Cancer Research 2007 Sep 1;13(17):5226-26. 
49. Hoyos V, Savoldo B, Dotti G. Genetic modification of human T lymphocytes for the treatment of hematologic malignancies. Haematol-Hematol J 2012 Nov;97(11):1622-31.

* Related to hematologic malignancies, but a comprehensive article by Hoyos and colleagues detailing modified T Lymphocytes

50. Carpenito C, Milone MC, Hassan R, Simonet JC, Lakhal M, Suhoski MM, et al. Control of large, established tumor xenografts with genetically retargeted human T cells containing CD28 and CD137 domains. P Natl Acad Sci USA 2009 Mar 3;106(9):3360-65.

51. Schuberth PC, Hagedorn C, Jensen SM, Gulati P, van den Broek M, Mischo A, et al. Treatment of malignant pleural mesothelioma by fibroblast activation protein-specific redirected T cells. J Transl Med 2013 Aug 12;11.

52. Imai K, Takaoka A. Comparing antibody and small-molecule therapies for cancer. Nature reviews Cancer 2006 Sep;6(9):714-27.

* Detailed article comparing antibody and small-molecule therapy for mesothelioma by Imai and Takaoka.

53. Hartmann JT, Haap M, Kopp HG, Lipp HP. Tyrosine kinase inhibitors - a review on pharmacology, metabolism and side effects. Current drug metabolism 2009 Jun;10(5):470-81.

54. Arora A, Scholar EM. Role of tyrosine kinase inhibitors in cancer therapy. The Journal of pharmacology and experimental therapeutics 2005 Dec;315(3):971-9.

55. Pache JC, Janssen YM, Walsh ES, Quinlan TR, Zanella CL, Low RB, et al. Increased epidermal growth factor-receptor protein in a human mesothelial cell line in response to long asbestos fibers. The American Journal of Pathology 1998 Feb;152(2):333-40.

56. Suzuki Y, Murakami H, Kawaguchi K, Tanigushi T, Fujii M, Shinjo K, et al. Activation of the PI3K-AKT pathway in human malignant mesothelioma cells. Molecular medicine reports 2009 Mar-Apr;2(2):181-8.

57. Janne PA, Taffaro ML, Salgia R, Johnson BE. Inhibition of epidermal growth factor receptor signaling in malignant pleural mesothelioma. Cancer research 2002 Sep $15 ; 62(18): 5242-7$.

58. Lurje G, Lenz HJ. EGFR Signaling and Drug Discovery. Oncology-Basel 2009;77(6):400-10.

59. Mezzapelle R, Miglio U, Rena O, Paganotti A, Allegrini S, Antona J, et al. Mutation analysis of the EGFR gene and downstream signalling pathway in histologic samples of malignant pleural mesothelioma. British journal of cancer 2013 Apr 30;108(8):1743-9.

60. Govindan R, Kratzke RA, Herndon JE, 2nd, Niehans GA, Vollmer R, Watson D, et al. Gefitinib in patients with malignant mesothelioma: a phase II study by the Cancer and Leukemia Group B. Clinical cancer research : an official journal of the American Association for Cancer Research 2005 Mar 15;11(6):2300-4. 
61. Garland LL, Rankin C, Gandara DR, Rivkin SE, Scott KM, Nagle RB, et al. Phase II Study of Erlotinib in Patients With Malignant Pleural Mesothelioma: A Southwest Oncology Group Study. Journal of Clinical Oncology 2007 2007/06/10;25(17):2406-13.

62. Jackman DM, Kindler HL, Yeap BY, Fidias P, Salgia R, Lucca J, et al. Erlotinib plus bevacizumab in previously treated patients with malignant pleural mesothelioma. Cancer 2008 Aug 15;113(4):808-14.

63. Destro A, Ceresoli GL, Falleni M, Zucali PA, Morenghi E, Bianchi P, et al. EGFR overexpression in malignant pleural mesothelioma. An immunohistochemical and molecular study with clinico-pathological correlations. Lung cancer 2006 Feb;51(2):207-15.

64. Cortese JF, Gowda AL, Wali A, Eliason JF, Pass HI, Everson RB. Common EGFR mutations conferring sensitivity to gefitinib in lung adenocarcinoma are not prevalent in human malignant mesothelioma. International journal of cancer 2006 Jan 15;118(2):521-2.

65. Kurai J, Chikumi H, Hashimoto K, Takata M, Sako T, Yamaguchi K, et al. Therapeutic antitumor efficacy of anti-epidermal growth factor receptor antibody, cetuximab, against malignant pleural mesothelioma. Int J Oncol 2012 Nov;41(5):1610-18.

66. Hanahan D, Weinberg RA. Hallmarks of cancer: the next generation. Cell 2011 Mar 04;144(5):646-74.

67. Hoeben A, Landuyt B, Highley MS, Wildiers H, Van Oosterom AT, De Bruijn EA. Vascular endothelial growth factor and angiogenesis. Pharmacological reviews 2004 Dec;56(4):549-80.

68. Aoe K, Hiraki A, Tanaka T, Gemba K, Taguchi K, Murakami T, et al. Expression of vascular endothelial growth factor in malignant mesothelioma. Anticancer research 2006 Nov-Dec;26(6C):4833-6.

69. Demirag F, Unsal E, Yilmaz A, Caglar A. Prognostic significance of vascular endothelial growth factor, tumor necrosis, and mitotic activity index in malignant pleural mesothelioma. Chest 2005 Nov;128(5):3382-7.

70. Fujimoto N, Gemba K, Kishimoto T. Clinical significance of serum vascular endothelial growth factor in malignant pleural mesothelioma. Journal of thoracic oncology : official publication of the International Association for the Study of Lung Cancer 2011 May;6(5):971-2.

71. Cohen MH, Gootenberg J, Keegan P, Pazdur R. FDA drug approval summary: Bevacizumab (Avastin (R)) plus carboplatin and paclitaxel as first-line treatment of advanced/metastatic recurrent nonsquamous non-small cell lung cancer. Oncologist 2007;12(6):713-18.

72. Koukourakis GV, Sotiropoulou-Lontou A. Targeted therapy with bevacizumab (Avastin) for metastatic colorectal cancer. Clin Transl Oncol 2011 Oct;13(10):710-14.

73. Escudier B, Cosaert J, Jethwa S. Targeted therapies in the management of renal cell carcinoma: role of bevacizumab. Biologics : targets \& therapy 2008 09/;2(3):517-30. 
74. Della Pepa C, Banerjee S. Bevacizumab in combination with chemotherapy in platinum-sensitive ovarian cancer. Oncotargets Ther 2014;7:1025-32.

75. Dowell JE, Dunphy FR, Taub RN, Gerber DE, Ngov L, Yan J, et al. A multicenter phase II study of cisplatin, pemetrexed, and bevacizumab in patients with advanced malignant mesothelioma. Lung cancer 2012 Sep;77(3):567-71.

76. Zalcman G, Mazieres J, Margery J, Greillier L, Audigier-Valette C, Moro-Sibilot D, et al. Bevacizumab for newly diagnosed pleural mesothelioma in the Mesothelioma Avastin Cisplatin Pemetrexed Study (MAPS): a randomised, controlled, open-label, phase 3 trial. Lancet 2016 Apr 02;387(10026):1405-14.

77. Dudek AZ, Pang H, Kratzke RA, Otterson GA, Hodgson L, Vokes EE, et al. Phase II study of dasatinib in patients with previously treated malignant mesothelioma (cancer and leukemia group B 30601): a brief report. Journal of thoracic oncology : official publication of the International Association for the Study of Lung Cancer 2012 Apr;7(4):755-9.

78. Papa S, Popat S, Shah R, Prevost AT, Lal R, McLennan B, et al. Phase 2 study of sorafenib in malignant mesothelioma previously treated with platinum-containing chemotherapy. Journal of thoracic oncology : official publication of the International Association for the Study of Lung Cancer 2013 Jun;8(6):783-7.

79. Belani CP, Yamamoto N, Bondarenko IM, Poltoratskiy A, Novello S, Tang J, et al. Randomized phase II study of pemetrexed/cisplatin with or without axitinib for nonsquamous non-small-cell lung cancer. Bmc Cancer 2014 Apr 25;14.

80. Buikhuisen WA, Scharpfenecker M, Griffioen AW, Korse CM, van Tinteren H, Baas P. A Randomized Phase II Study Adding Axitinib to Pemetrexed-Cisplatin in Patients with Malignant Pleural Mesothelioma: A Single-Center Trial Combining Clinical and Translational Outcomes. Journal of Thoracic Oncology 2016 May;11(5):758-68.

81. Garland LL, Chansky K, Wozniak AJ, Tsao AS, Gadgeel SM, Verschraegen CF, et al. Phase II study of cediranib in patients with malignant pleural mesothelioma: SWOG S0509. Journal of thoracic oncology : official publication of the International Association for the Study of Lung Cancer 2011 Nov;6(11):1938-45.

82. Nowak AK, Millward MJ, Creaney J, Francis RJ, Dick IM, Hasani A, et al. A Phase II Study of Intermittent Sunitinib Malate as Second-Line Therapy in Progressive Malignant Pleural Mesothelioma. Journal of Thoracic Oncology 2012 Sep;7(9):1449-56.

83. Ropero S, Esteller M. The role of histone deacetylases (HDACs) in human cancer. Mol Oncol 2007 Jun;1(1):19-25.

84. Neuzil J, Swettenham E, Gellert N. Sensitization of mesothelioma to TRAIL apoptosis by inhibition of histone deacetylase: role of Bcl-xL down-regulation. Biochemical and biophysical research communications 2004 Jan 30;314(1):186-91.

85. Kelly WK, O'Connor OA, Krug LM, Chiao JH, Heaney M, Curley T, et al. Phase I study of an oral histone deacetylase inhibitor, suberoylanilide hydroxamic acid, in patients with advanced cancer. Journal of Clinical Oncology 2005 Jun 10;23(17):3923-31. 
86. Krug LM, Kindler HL, Calvert H, Manegold C, Tsao AS, Fennell D, et al. Vorinostat in patients with advanced malignant pleural mesothelioma who have progressed on previous chemotherapy (VANTAGE-014): a phase 3, double-blind, randomised, placebo-controlled trial. Lancet Oncol 2015 Apr;16(4):447-56.

87. Ramalingam SS, Belani CP, Ruel C, Frankel P, Gitlitz B, Koczywas M, et al. Phase II study of belinostat (PXD101), a histone deacetylase inhibitor, for second line therapy of advanced malignant pleural mesothelioma. Journal of thoracic oncology : official publication of the International Association for the Study of Lung Cancer 2009 Jan;4(1):97-101.

88. Sulzmaier FJ, Jean C, Schlaepfer DD. FAK in cancer: mechanistic findings and clinical applications. Nature Reviews Cancer 2014 Sep;14(9):598-610.

89. Poulikakos PI, Xiao GH, Gallagher R, Jablonski S, Jhanwar SC, Testa JR. Reexpression of the tumor suppressor NF2/merlin inhibits invasiveness in mesothelioma cells and negatively regulates FAK. Oncogene 2006 Sep 28;25(44):5960-68.

90. Soria JC, Gan HK, Blagden SP, Plummer R, Arkenau HT, Ranson M, et al. A phase I, pharmacokinetic and pharmacodynamic study of GSK2256098, a focal adhesion kinase inhibitor, in patients with advanced solid tumors. Annals of oncology : official journal of the European Society for Medical Oncology 2016 Dec;27(12):2268-74.

91. Fennell DA, McDowell C, Busacca S, Webb G, Moulton B, Cakana A, et al. Phase II Clinical Trial of First or Second-Line Treatment with Bortezomib in Patients with Malignant Pleural Mesothelioma. Journal of Thoracic Oncology 2012 Sep;7(9):1466-70.

92. Nowak AK, Brown C, Millward MJ, Creaney J, Byrne MJ, Hughes B, et al. A phase II clinical trial of the Vascular Disrupting Agent BNC105P as second line chemotherapy for advanced Malignant Pleural Mesothelioma. Lung cancer 2013 Sep;81(3):422-27.

93. Kalra N, Zhang J, Yu Y, Ho M, Merino M, Cao L, et al. Efficacy of anti-insulin-like growth factor I receptor monoclonal antibody cixutumumab in mesothelioma is highly correlated with insulin growth factor-I receptor sites/cell. International journal of cancer 2012 Nov 01;131(9):2143-52.

94. Porta C, Paglino C, Mutti L. Ranpirnase and its potential for the treatment of unresectable malignant mesothelioma. Biologics : targets \& therapy 2008 Dec;2(4):601-9.

95. Costanzi J, Sidransky D, Navon A, Goldsweig H. Ribonucleases as a novel proapoptotic anticancer strategy: Review of the preclinical and clinical data for ranpirnase. Cancer Invest 2005;23(7):643-50.

96. Chu W-M. Tumor necrosis factor. Cancer letters 2013 10/22;328(2):222-25.

97. Stevenson JP, Kindler HL, Papasavvas E, Sun J, Jacobs-Small M, Hull J, et al. Immunological effects of the TGF $\beta$-blocking antibody GC1008 in malignant pleural mesothelioma patients. Oncoimmunology 2013;2(8):e26218.

98. Feig C, Jones JO, Kraman M, Wells RJ, Deonarine A, Chan DS, et al. Targeting CXCL12 from FAP-expressing carcinoma-associated fibroblasts synergizes with anti-PD-L1 immunotherapy in pancreatic cancer. Proc Natl Acad Sci U S A 2013 Dec 10;110(50):202127. 
99. Kalra N, Ashai A, Xi L, Zhang J, Avital I, Raffeld M, et al. Patients with peritoneal mesothelioma lack epidermal growth factor receptor tyrosine kinase mutations that would make them sensitive to tyrosine kinase inhibitors. Oncology reports 2012 Jun;27(6):1794800 .

100. Enomoto Y, Kasai T, Takeda M, Takano M, Morita K, Kadota E, et al. Epidermal growth factor receptor mutations in malignant pleural and peritoneal mesothelioma. Journal of clinical pathology 2012 Jun;65(6):522-7.

101. Graziani I, Eliasz S, De Marco MA, Chen Y, Pass HI, De May RM, et al. Opposite effects of Notch-1 and Notch-2 on mesothelioma cell survival under hypoxia are exerted through the Akt pathway. Cancer research 2008 Dec 01;68(23):9678-85.

102. Goudarzi H, Iizasa H, Furuhashi M, Nakazawa S, Nakane R, Liang S, et al. Enhancement of in vitro cell motility and invasiveness of human malignant pleural mesothelioma cells through the HIF-1alpha-MUC1 pathway. Cancer Lett 2013 Oct 01;339(1):82-92.

103. Ivanov S, Liao SY, Ivanova A, Danilkovitch-Miagkova A, Tarasova N, Weirich G, et al. Expression of hypoxia-inducible cell-surface transmembrane carbonic anhydrases in human cancer. The American Journal of Pathology 2001 Mar;158(3):905-19.

104. Francis RJ, Segard T, Morandeau L, Lee YC, Millward MJ, Segal A, et al. Characterization of hypoxia in malignant pleural mesothelioma with FMISO PET-CT. Lung cancer 2015 Oct;90(1):55-60.

105. Manente AG, Valenti D, Pinton G, Jithesh PV, Daga A, Rossi L, et al. Estrogen receptor beta activation impairs mitochondrial oxidative metabolism and affects malignant mesothelioma cell growth in vitro and in vivo. Oncogenesis 2013 Sep 23;2:e72. 